\title{
Los caminos de la arquitectura rural en el nor-oriente
}

\author{
Rosana Correa Álamo
}

\section{I.-Introducción}

Este artículo es parte de un trabajo de investigación de la arquitectura rural en un sector del norte del Perú denominado: corredor nor-oriental del Marañón, que hoy se promociona con fines turísticos. Pero su connotación va más allá de un mero circuito, pues fue un eje histórico de jerarquía regional que integró culturas como la Mochica, Chimú, Cajamarca, Chachapoya y otras que ocuparon áreas geográficas de Ecuador, Colombia y Brasil.

Las evidencias arquitectónicas demuestran que los desarrollos regionales en cada una de estas zonas, que no necesariamente coinciden con los límites geográficos que hoy tiene el Perú, se movilizaron constantemente en un afán por acceder a productos de otros espacios geográficos, con el consiguiente intercambio de costumbres y tecnologías. Por otro lado, en tiempo de las conquistas inca y española, ocurrieron movilizaciones forzadas de poblaciones enteras, que explican la importación de patrones culturales de otros contextos, caso de los pueblos de Chetilla, en Cajamarca o Lamas, en San Martín.
Este trabajo es una puerta de ingreso a otras muchas investigaciones y, por lo tanto, presenta limitaciones a la vez que abre interrogantes. Llama la atención en esta zona, la presencia contundente de los pueblos amazónicos en el desarrollo cultural del norte, lo que se observa en las expresiones originales de tecnología y diseño constructivo que se consolidan en las obras de arquitectura rural del hombre de hoy.

La tesis subyacente es que la importancia de estas obras menores, pero numerosas, radica, por un lado, en que esta arquitectura viva facilita el entendimiento de patrones constructivos utilizados en épocas pasadas; y por otro, muestra como la tradición estilística y tecnológica se ha venido transmitiendo de generación en generación. Esta arquitectura sencilla se las ingenia para dar buen uso a materiales de la zona como: el barro, la madera, la piedra, la caña y las hojas de palma; además de permitir observar patrones que son producto de un mestizaje de etnias, lo cual nos ayuda también a entender los hechos históricos. 


\section{II.-Marco geográfico}

El norte peruano se caracteriza por tener una cordillera estrecha, con dos flancos diferenciados: un occidente seco y un oriente amazónico húmedo. La divisoria de aguas, que separa a las vertientes occidental y oriental, no llega a los 4000 metros de altitud, con ausencia de cumbres nevadas a diferencia de los andes del sur. En el extremo norte de esta zona, cada vez más baja, se puede ver la influencia climática amazónica evidenciada en la flora y la fauna tropical.

En la vertiente occidental, desde la frontera con Ecuador hasta Lambayeque, vemos una costa que se desarrolla con un bosque seco y periódicas precipitaciones en verano, con temperaturas anuales que fluctúan entre los $20^{\circ} \mathrm{C}$ y $25^{\circ} \mathrm{C}$. También caracteriza a este norte occidental la presencia del Fenómeno del Niño que se presenta irregularmente en el Océano Pacífico provocando perturbaciones climáticas en la costa y en las vertientes andinas que limitan con ésta.

En la vertiente oriental vemos cañor es profundos que sobrepasan los 3000 metros de desnivel, cuyos fondos de valle están por debajo de los 2000 metros, existiendo microclimas de tipo tropical con altas temperaturas durante todo el año. En los pisos medios de esta zona cordillerana se desarrolla una importante actividad agrícola de altura, con exponentes en Huancabamba y Ayabaca en Piura, Chachapoyas en Amazonas, Cajamarca y la sierra interandina de la Libertad (ver dibujo $n^{\circ} 1$ ).

El hombre antiguo hizo obras de ingeniería hidráulica en ambas vertientes, como el canal de Cumbemayo en Cajamarca o el de la Cumbre construido por los chimú para trasladar agua del río Chicama al Moche, así como los andenes en la zona de Pajatén y Chachapoyas.

Los bosques de Jaén y San Ignacio, en el nor-oriente, constituyen los más ricos en masa forestal nativa de toda la cordillera en el Perú.

El hombre de este medio geográfico ha ocupado un área privilegiada, con montañas que llegan a los 3800 m.s.n.m., las cuales -aunque frías- no llegan a congelarse y se caracterizan por su constante humedad. Más interesante aún es ver como debajo y muy cerca de esta jalca fría se desarrollan las quebra- dibujo 1

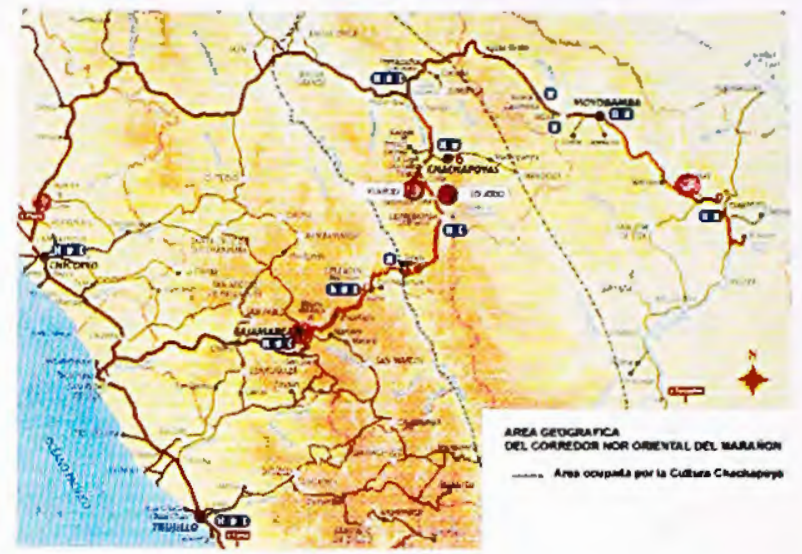

das boscosas denominadas "bosque muy húmedo, montano sub tropical" con presencia de orquídeas, helechos, etc. Desdichadamente estas laderas tienen delgadas capas de suelo, lo que hace frágil al ecosistema debido a los deslizamientos constantes.

Por el fondo discurren ríos y riachuelos que conforman valles cálidos productores de café, caña de azúcar y cítricos, donde se alcanzan altas temperaturas diurnas que descienden en las noches.

\section{III.-Presencia del hombre}

Se han encontrado evidencias de ocupación primitiva en Bagua y Utcubamba, con una antigüedad de 6000 años, donde el hombre se expresó a través de dibujos geométricos con representaciones humanas y animales hechos en la roca con pintura roja a base de tierra. El hombre, en su fase evolutiva, dejó evidencias de elaboración de cerámica entre los años 1500 y 1200 a.C. aproximadamente (Bagua- Ruth Shady) y 1800 a 900 a.C. (Abiseo).

Luego se encuentra la ocupación cultural del grupo étnico de los chilcho, confederación de los chachapoya que ocupó la vertiente oriental andina y las regiones montañosas adyacentes de Amazonas, al este de Leimebamba y al nor-este de Bolívar entre los ríos de Huabayacu y el ahora llamado Chilchos; y la ocupación propia de los chachapoya, con límite entre el río Huallaga por el este, la actual provincia de Pataz (La Libertad) por 
el sur (Blas Valera) y la zona sur de la actual provincia de Bagua por el norte.

Parece ser que los chachapoya tuvieron una importante relación de intercambio con culturas vecinas de la vertiente occidental, lo cual fortaleció su desarrollo cultural y tecnológico, teniendo que enfrentarse constantemente a los chilcho que se caracterizaron por ser un grupo étnico independiente y difícil de gobernar.

Cuando los incas quisieron conquistar esta parte del territorio fueron los chilcho los grandes rebeldes, sufriendo posteriormente la división y dispersión de su gente por orden de los conquistadores, mientras los chachapoya sobrevivieron y convivieron políticamente con ellos.

Así podemos advertir la presencia de los chilcho en una región andina como Chetilla en Cajamarca, producto de una reubicación; pero también, el arribo de gente de las etnias Chupaychu, Lucana, Wanka, Cañari, Cajamarca, Lambayeque, Ferreñafe y Saña.

\section{IV.- Los chachapoya}

\section{Sembrando caminos y pueblos en las cumbres}

La cultura Chachapoya se desarrolló en el ámbito geográfico de lo que hoy son los departamentos de Amazonas y San Martín. Por sus propias manifestaciones culturales es catalogada como amazónica en algunos casos y andina en otros. Cuando hablamos de la cultura Chachapoya se está considerando la presencia del grupo étnico de los chilcho que controlaba la vertiente oriental andina y las regiones montañosas adyacentes al este de Leimebamba.

Existen interesantes hipótesis sobre los orígenes de esta cultura, las cuales podríamos sintetizar de la siguiente manera:

- A partir de los restos de cerámica encontrados en el complejo arquitectónico Kuelap, se considera que la época más antigua de los chachapoya está entre los años 200 a.C. y 400 d.C., en el período en que se consolidaba la cultura Cajamarca al oeste, la Mochica en la costa norte y la Nazca en la costa sur. Y donde posiblemente se establece una relación cultural con los cajamarca (Ruiz Estrada).

- La cultura Chachapoya tiene su origen, a partir del año 500d.C., en la ocupación dispersa de la cultura Tiahuanaco-Wari en esta zona (2000 a 3000 m.s.n.m.); por lo que se cataloga a esta cultura como una civilización de tradición andina (Kauffman Doig).

- La etapa prechachapoya se relaciona a un origen amazónico posiblemente conectado con la tradición originaria de Ecuador y Colombia. Las investigaciones idiomáticas de Paul Rivet hablan de un parentesco con el chibcha y el caribe, en Colombia.

- Las interpretaciones hechas por Peter Lerche, de la iconografía chachapoya, revelan un posible origen amazónico, relacionado al grupo étnico de los chilcho a través de la quebrada honda del río Marañon que corre de sur a norte y separa esta zona del resto del ande con un relativo aislamiento de los acontecimientos panandinos.

\section{Organización de pueblos $y$ curacazgos}

Los chachapoya, con una población aproximada de 50 mil habitantes, ocupaban una extensión de 278 por 111 kilómetros (Garcilaso 1963:293). Se organizaban en "ayllus", y varios ayllus en un "llajta". A su vez, un cierto número de llajtas conformaban una "parcialidad" o "curacazgo", que eran políticamente autónomos.

Los chilcho, grupo de los chachapoya, planificaron una estructurada red de caminos comunicando las regiones montañosas y la sierra andina, así como la consolidación de corredores naturales, por donde realizaban movimientos migratorios desde la zona nor-andina o peregrinaciones desde el oriente como la de los tupi-guarani (Cobo 1964 II:33).

Su ubicación estratégica les permitió realizar intercambios con culturas andinas y amazónicas, como se puede ver en el Gran Pajatén. EI trabajo de la piedra convertida en cabezas clavas de humanos y felinos, al estilo de la cultura Recuay, y el uso de tocados hechos en plumas de loro con estructura de caña, son muy parecidos a los hechos actualmente en la Selva Baja. Ello ex- 
plicaría el gran interés de los incas por dominar estas tierras que eran una puerta de ingreso a los campos de cacao, vainilla, madera de palmera chonta y hábitat de animales codiciados por su piel como el jaguar.

Así, los chachapoya construyeron pueblos sobre la cumbre de los cerros, a una altura aproximada de 2800 y 3400 m.s.n.m., que albergaban entre 600 y 3000 personas. Ellos estaban organizados en señoríos o curacazgos, de los cuales se pueden mencionar algunos ejemplos como: Utac (Mariscal Cáceres) con mil viviendas, Xalca (Magdalena y La Jalca) con dos mil viviendas, Chilcho (Leymebamba) con cinco mil familias, Pipos (no se cuenta con datos de población) y Levanto con 2500 familias, que más tarde fue centro administrativo de los incas.

Peter Lerche cuenta que en sus caminatas por las alturas encontró muchos conjuntos urbanos aún no estudiados, con monumentales muros de contención, albergando entre 100 y 400 recintos de piedra, generalmente en forma circular y con muy pocos ejemplares rectangulares. Quedan hoy los vestigios de los pueblos construidos antes de los incas como Rosurco, Llui, Navar, Yálape, Puyán, San Pedro de Washpa dentro del curacazgo Levanto; La Congona cerca de Leymebamba o Purun Llaqta con 400 construcciones circulares en Soloco. Así mismo, los chachapoya construyeron algunos pueblos en la parte baja del valle como los de Macro y Tuich, cerca al río Utcubamba, que posiblemente tenían fines religiosos, según Lerche.

\section{V.- Kuelap \\ Pueblo construido sobre murallas de piedra}

El Dr. Alfredo Narváez atribuye la construcción de este pueblo a un período que abarca los años 800 d.C y 1300 d.C, sobre los 3000 m.s.n.m., en una angosta y alargada meseta, lo que obligó a los arquitectos a efectuar una particular distribución del espacio urbano.

Se tuvo como prioridad edificar en la cumbre más alta, definiendo un hito arquitectónico de carácter regional, con una extensión de 450 ha. En la cima del cerro se ubicó, en el lado oeste de esta gran área, la "Fortaleza Kuelap", mientras que al otro extremo, en las laderas, se concentró el conjunto de viviendas. A cien metros de la Fortaleza, en la parte menos accesible por la presencia de barrancos, se alineó un conjunto de sarcófagos en una espacio cóncavo del cerro, que ocupa setenta metros de largo por dos metros de ancho.

Kuelap fue construido por los chachapoya, hombres de origen amazónico, que luego de ser vencidos por los incas encontraron la forma de convivir con ellos a través de la repartición de poderes en cada curacazgo. Ello se evidencia en las pocas intervenciones de los vencedores en la tecnología y diseño arquitectónico. Este complejo se desarrolló siguiendo patrones urbanos y de ocupación que describiremos seguidamente:

- Ocupación de la cima más alta y angosta del cerro por un doble muro de contención ondulante, de veinte metros de alto, que encierra un área de 584 metros de largo, por 110 de ancho.

foto ${ }^{\circ}$

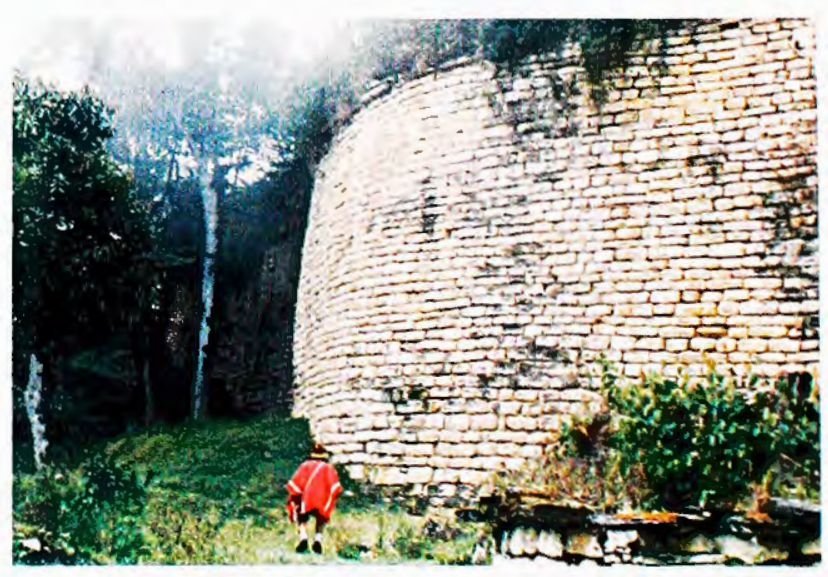

- Uso de plataformas escalonadas sobre este muro de contención, para el acondicionamiento urbano del conjunto arquitectónico. Dada la estrechez del área de ocupación, estas plataformas son angostas y cuentan solamente con uno o dos ejes de circulación irregular, que dan acceso a los recintos de piedra, sin definir una trama de calles que creen espacios urbanos configurados (ver dibujo $\mathrm{n}^{\circ} 2$ ).

- En la primera plataforma se encuentran las edificaciones circulares. La distribución urbana de éstas es altamente concentrada gracias al aglutinamiento de recintos en forma 
tanto lineal como grupal. Estas unidades son independientes a pesar de estar muy cerca, sin comunicación entre sí por pasajes o corredores, pero con contacto hacia el exterior (ver dibujo $n^{\circ} 3$ ).

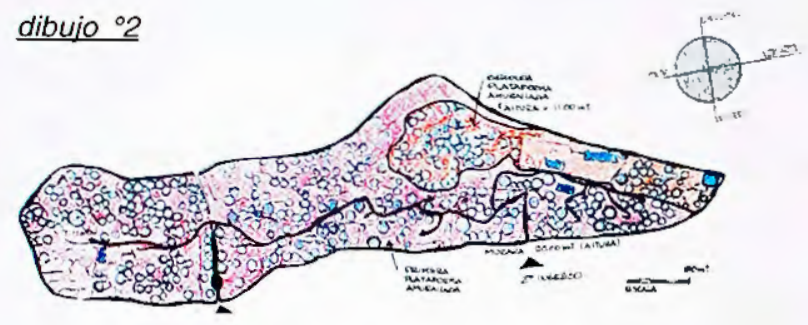

dibujo ${ }^{\circ} 3$

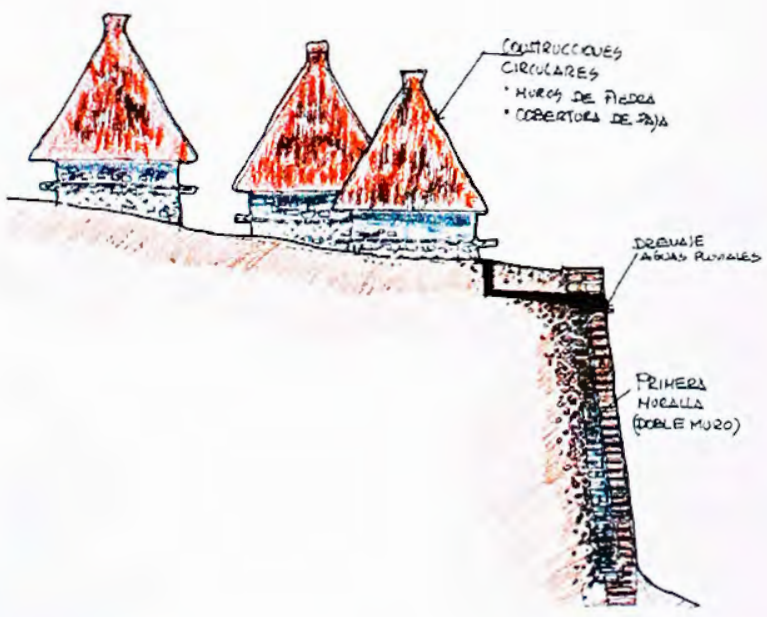

- Los tres accesos están orientados hacia el Este y Oeste, lo que permitió aprovechar el sentido de la pendiente y utilizar el frente más alargado del cerro. Estos accesos son corredores que, a manera de zaguanes de tres metros de ancho, fueron techados con "falsa bóveda de piedra" y tienen la particularidad de angostarse progresivamente a lo largo de una pendiente pronunciada que se eleva $20 \mathrm{~m}$. y recorre $50 \mathrm{~m}$. hasta terminar en un espacio mínimo de $70 \mathrm{~cm}$.

- Existen hipótesis que apuntan a que, por el carácter militar del conjunto, se tenía que recurrir a estos artificios arquitectónicos de control del acceso, que mantenían además el factor sorpresa en el diseño urbano.
- En la muralla principal se pueden ver ductos de drenaje de aguas de lluvia que vienen desde el interior y se comunican con los de los recintos circulares. Así mismo, se pueden apreciar los alto relieves hechos en la misma piedra con motivos antropomorfos (ver dibujo $n^{\circ} 3$ ).

\section{Principios de la arquitectura chachapoya en Kuelap}

En Kuelap, las edificaciones tienen características que las tipifican y diferencian de la arquitectura andina producida por otras culturas. Tratando de ordenar y sistematizar lo hasta ahora encontrado, se puede señalar lo siguiente:

- Los muros perimétricos de contención tienen una mediana pendiente, desde la base del muro hasta su cabecera, para una eficiente estructuración del conjunto urbano. Este patrón no se aplica en la construcción de las habitaciones, cuyos muros no tienen el desplome característico visto en otras culturas, pero sí presentan un engrosamiento en la altura media del recinto.

- La construcción de los muros se realizó con bloques de piedra unidos con mortero de barro, alternándolos, cada cierta cantidad de hiladas, con finas lajas. Los bloques tienen un ligero almohadillado que algunas veces desarrolla alto relieves con motivos iconográficos.

- Dada la pobreza del suelo y las constantes lluvias se tuvo la precaución de elevar cada uno de los recintos, pero no con pilotes, vigas o entablado de madera sobre el nivel del suelo, sino con el acondicionamiento de un relleno confinado con un muro de piedra circular, finamente decorado con frisos romboidales. Es interesante ver que este sobrecimiento se protegió con un alero hecho de lajas de piedra, con lo cual aseguraban la perpetuidad del edificio. Este muro base permitió acondicionar el edificio a la pendiente dominante, con lo cual su altura pudo ascender desde los $80 \mathrm{~cm}$. hasta los tres metros (ver foto ${ }^{\circ} 2$ ). 
toto ${ }^{\circ} 2$

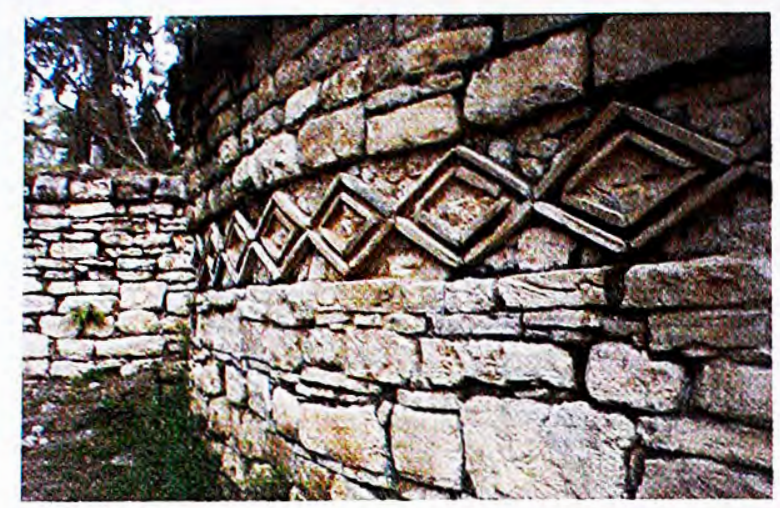

- Se observa el predominio de la forma circular en las construcciones, las cuales se concentran en la primera plataforma, que posiblemente fueron viviendas y, en menor proporción, edificios públicos. Su acomodo y distribución son irregulares y aparentemente no siguen un orden establecido lo que permitiría adiciones no planificadas. Es interesante ver una modalidad de recintos semicirculares que hacen recordar el "Torreón del Inca" en Machu Picchu, y que parecen haber tenido un uso administrativo.

- Las construcciones de forma rectangular, que se ubican en la segunda plataforma, a once metros de la primera, parecen dividirse en sectores según los usos ceremonial y residencial de jerarquía, distinguiéndose por la presencia de un torreón defensivo denominado "El Tintero". Éste tiene un aspecto particular de cono invertido que reta a las leyes de gravedad. Los recintos en forma de "U" están orientados hacia el Este u Oeste, aquí tampoco los recintos se comunican a través de corredores intemos.

- Los pisos fueron de piedra con argamasa de arcilla y piedras pequeñas, así mismo, los enlucidos parecen haber sido de arcilla con carbón, paja, restos de huesos e incrustaciones de cerámica. Se han encontrado pocas evidencias de pintura.

- Los techos, de acuerdo a las evidencias históricas encontradas por Langlois y Wiener en La Jalca, pueden haber sido estructuras cónicas de madera y caña cubiertas con paja tejida, similares a los existentes en el actual pueblo de La Jalca. Otra evidencia de importancia es la encontrada, a principios del siglo XVI por Vásquez de Espinoza en Luya, pueblo Kacta, donde se habla de un posible techo con falsa bóveda en piedra formando una "media naranja" en el exterior, lo cual es convenien- te para techar algunas edificaciones circulares con diámetros relativamente cortos. Tipo de techo que, por otro lado, es parte de nuestra tradición prehispánica (Huánuco, Lima, Cajamarca, etc.).

- La ornamentación de los muros es de piedra con frisos hundidos y con aplicación de laja formando rombos concéntricos. Estos frisos se aplicaban en la parte inferior de los muros debajo de los aleros bajos.

- Se observa también la construcción de pequeñas fosas subterráneas dentro de los recintos circulares, de aproximadamente metro y medio de profundidad, donde posiblemente se almacenaron alimentos deshidratados y que, en la fase final, se utilizaron como lugar de entierro (ver foto 3). Así mismo, aparecen hornacinas que muchas veces se confunden con otros nichos de menor tamaño en la parte alta.

foto 3

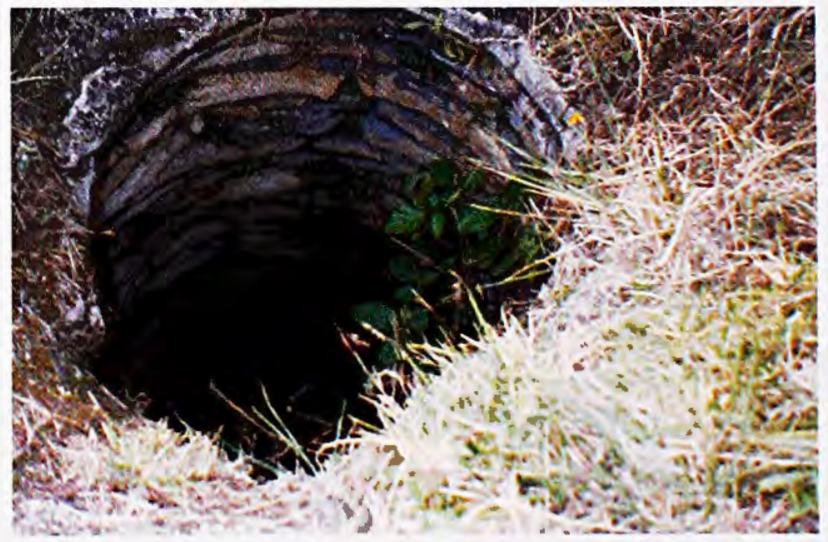

- Detalle en la jamba de la puerta, donde posiblemente hubo un sistema de articulación para el giro de una puerta de madera.

\section{VI.-Arquitectura viva en un pueblo rural, La Jalca}

\section{Un pueblo dibujado en las nubes}

A unos cuarenta kilómetros al este del complejo Kuelap se ubica un pueblo histórico llamado La Jalca (2500 m.s.n.m.) que se desarrolla sobre la cumbre de un cerro, de la misma manera que el 
complejo arquitectónico Kuelap. Es aquí donde el estudioso Langlois (1939) pudo ver el recinto circular de posible origen prehispánico que se describió anteriormente.

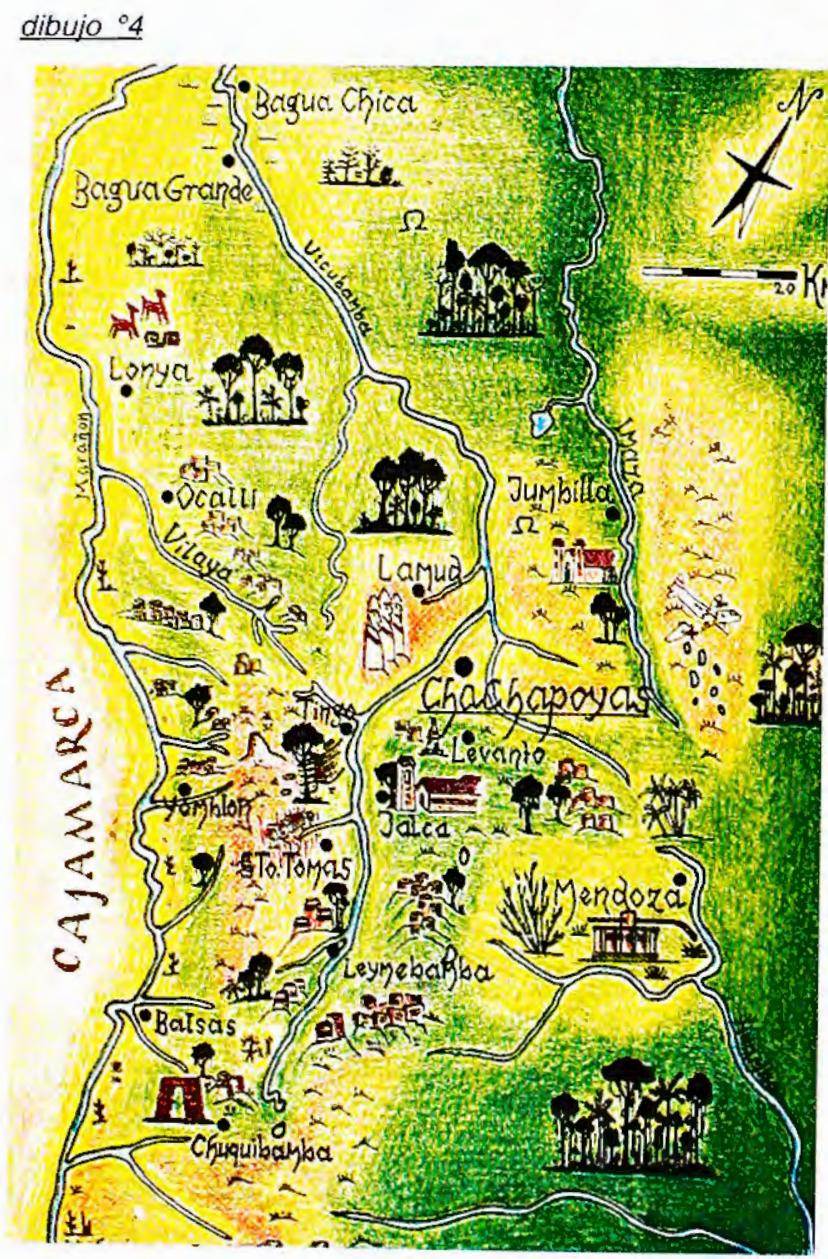

El pueblo La Jalca fue parte del curacazgo La Xalca, que ocupó extensiones que comprometían los distritos de Magdalena y La Jalca y que parece contó con dos mil familias, distribuidas sobre 500 km2, utilizando 3600 ha. para producir alimentos.

Loschachapoya explotarontierras de la zona quechua con la siembra de maíz y en menor porcentaje se utilizaron tierras de un mayor nivel altitudinal para la producción de tubérculos y granos andinos. Pero este curacazgo fue privilegiado, pues tuvo la particularidad de poder acceder, por su gran extensión agrícola, a seis pisos ecológicos. Como en otros curacazgos, reinaban dos líderes: el principal y el de "segunda persona", quien se ocupaba de los asuntos bélicos. La Xalca tuvo gran importancia en el ámbito regional por su ubicación como control de entrada de bienes provenientes de las montañas orientales.

Bajo el dominio inca La Xalca tuvo dos curacas y se repartió el poder entre los autóctonos chachapoya con su líder Zuta y los mitmaq / yana con su líder Guaman; aunque se dice que Zuta era viejo y no se le respetaba como al líder inca. Durante el dominio español Alonso de Alvarado fundó La Ciudad de la Frontera de los Chachapoyas en el mismo centro poblacional de la Jalca, pero por razones de desadaptación climática se reubicó la ciudad capital en Levanto, antiguo centro incaico; y, en 1545 en el lugar de la actual ciudad de Chachapoyas.

El pueblo La Xalca se densificó a partir de la aparición de enfermedades endémicas en los valles cálidos, migrando los sobrevivientes al Llajta principal de La Xalca, reuniéndose aquí los líderes de otros curacazgos que huían de las epidemias.

\section{Entre calles y acantilados}

Al desarrollarse sobre esta topografía la morfología urbana del pueblo se dibuja con estrechas calles que siguen la línea de las cumbres y terminan al borde de los acantilados, mientras los caminos de acceso se esparcen sobre las faldas de los cerros (ver foto $n^{\circ} 4$ ).

\section{foto ${ }^{\circ} 4$}

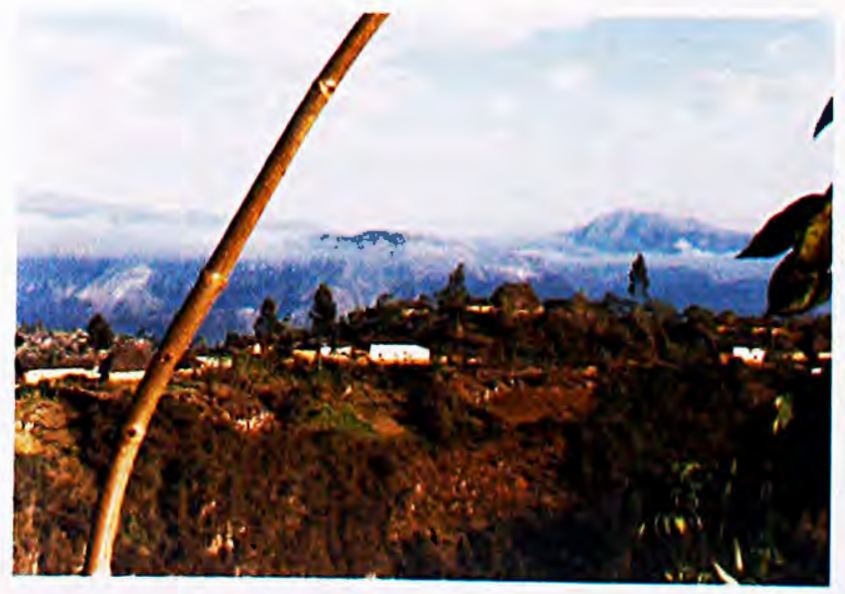

Otras características que tipifican el lugar son:

- El gran control del valle del Utcubamba desde La Jalca. 
- Los ejes viales que comunican con otros poblados y que son, por su ubicación en una cima angosta, de una sola calle, desmembrándose la traza urbana en varios ramales aislados uno del otro, siendo el único elemento comunicante la plaza central.

- Al igual que en Kuelap el asentamiento está flanqueado por acantilados y barrancos con fuerte pendiente hacia los lados, pero sin las murallas que tiene el complejo arqueológico.

- El patrón de diseño colonial define una traza urbana central en damero, de algunas pocas calles longitudinales y transversales, pero inmediatamente disperso hacia las pendientes.

\section{¿Arquitectura rural andina o amazónica?}

El asombro de cualquier visitante es inevitable al encontrar destacados ejemplos de arquitectura viva que nos remiten a las crónicas, escritas y dibujadas, sobre la tradición constructiva prehispánica o, por otro lado, a las construcciones rurales del hombre amazónico de hoy.

Cuando nos acercamos al pueblo La Jalca nuestra atención se fija en las pequeñas casas pegadas a los acantilados que definen sus muros con maderos gruesos entrecruzados, formando un tramado muy denso tipo "muesca"' (ver foto 5), a la manera de la construcción rural en los países nórdicos. Siguiendo nuestro recorrido nos encontramos con casas de mayor tamaño, construidas en piedra o en tapial ${ }^{2}$ que muchas veces tienen un bordado con lajas de piedra en forma de rombos y zigzag, al estilo de la arquitectura chachapoya en Kuelap y otros lugares.

\section{foto ${ }^{\circ} 5$}

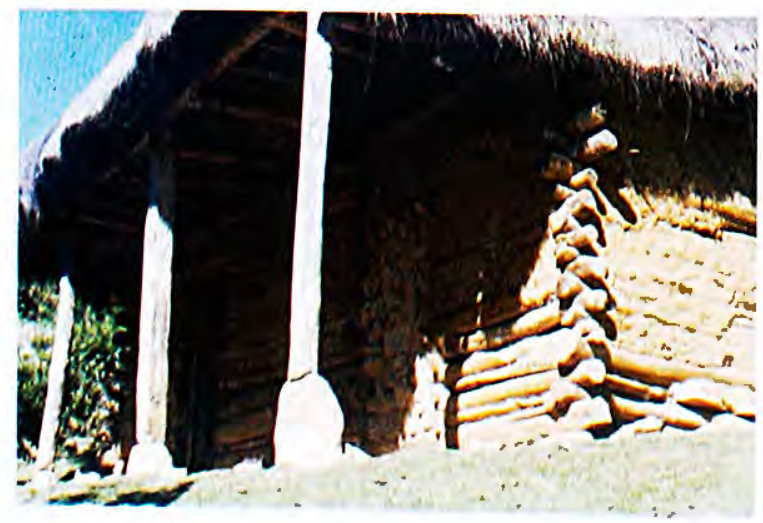

Lo característico en esta tipología son los grandes e inclinados techos cubiertos con paja sobre una gran estructura de madera y caña, amarradas con cuero de animal, que recuerdan los dibujos de Garcilaso de la Vega, Squier y Langlois o las "malocas" en la selva peruana.

La fuerte inclinación de estos techos da la posibilidad de tener un terrado sobre la casa para guardar la cosecha reciente y, por otro lado, una ramada sombreada delante, con una columnata de madera con pedestales tallados en piedra.

Los techos de paja son primorosamente tejidos y renovados cada dos años para soportar las Iluvias torrenciales. El ángulo aproximado de pendiente de estos techos es de $40^{\circ}$, para que las aguas de lluvia fluyan con facilidad.

\section{dibujo ${ }^{\circ} 5$}
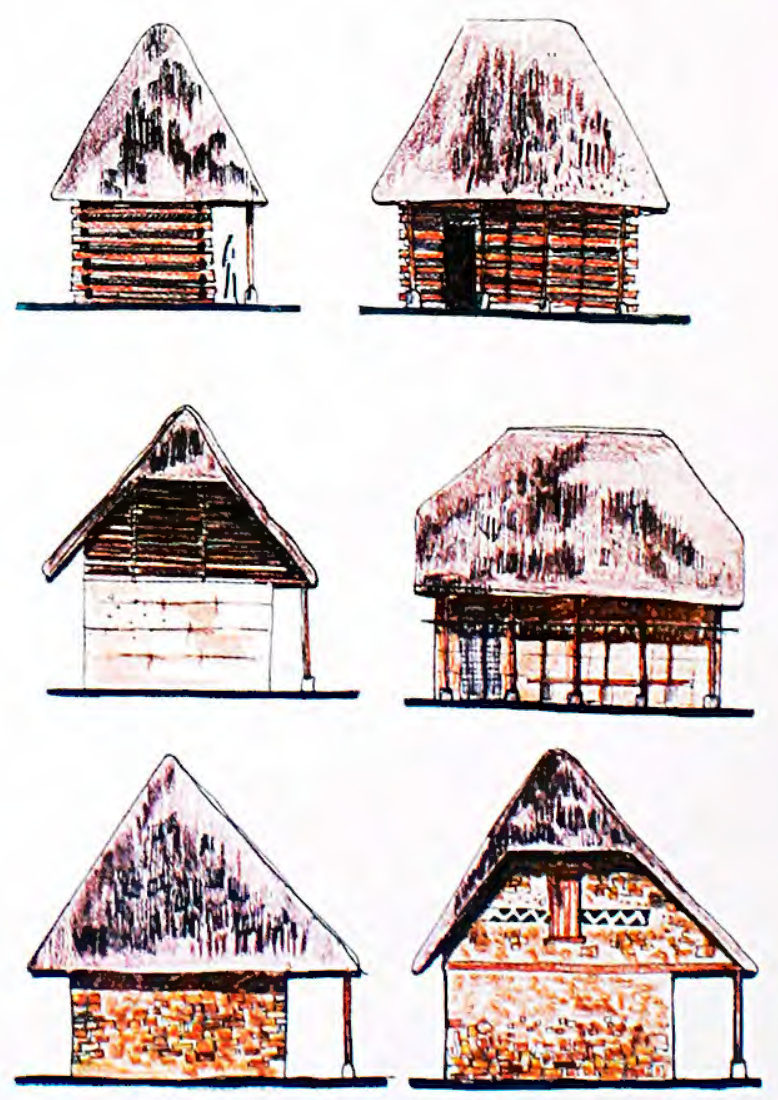

El pobbiador de la zona denemina así a los muros hechos con maderos entrecruzados. Técnica para construir muros con barro apisonato, conteniéndolo entre cajones de madera para luego presionarlo intensamente: $x$ pueden construir muros de dos a tres pisas Tipologia de vivienda rural en la selva, constrada con madera y hoja de palma. pave techos de gran inclinación y se sestienen sobre pilotes de madera para evitar la humedad del suelo y la protección de animales. 
Si establecemos un recorrido en el pueblo La Jalca veremos como se alternan las viviendas con grandes y empinados techos de paja, tal como lo describe Langlois. El estilo prehispánico es de casas de barro y piedra con techos de teja de arcilla soportados por gruesas y talladas columnas de madera. Pero, si seguimos un orden aproximado, veremos que alrededor de la plaza central se ubican las viviendas con techo de teja, mientras que en las afueras, cerca de los acantilados y quebradas, las casas con techos de paja van aumentando.

\section{foto ${ }^{\circ} 6$}

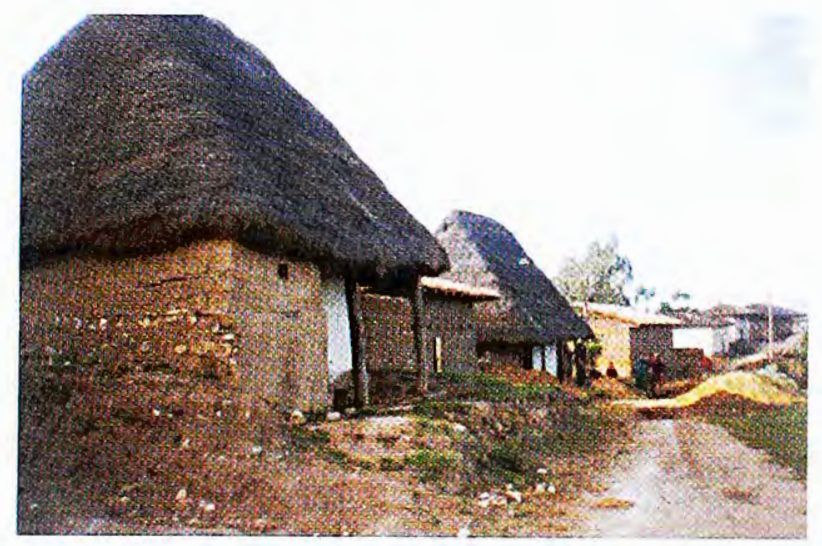

La casa con influencia colonial es construida con muros de piedra o barro, con altura de uno o dos pisos, ornamentada con balconería, columnas y capiteles tallados singularmente en madera. Muchas de estas casas tienen al interior un pequeño patio con balcones a los cuales se accede por una escalera de madera a veces tallada en un solo tronco. Cuando no existe este patio interior, el balcón corrido surge como parte de la fachada.

El hombre de La Jalca trabaja muy bien la madera y simplemente adapta el material que encuentra sin preocuparse si éste tiene dimensiones excesivas pero, como "material noble" que es, la madera nunca peca por exceso. dibujo ${ }^{\circ} 6$

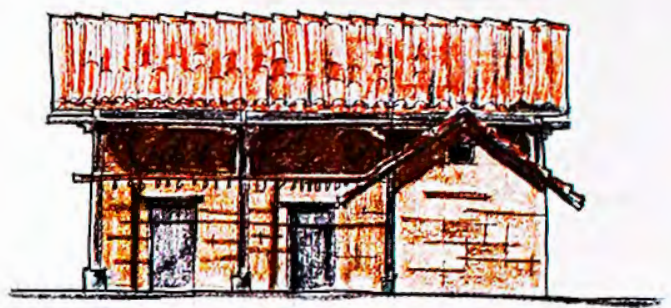

\section{El templo de piedra}

El edificio de la iglesia ocupa con sus muros laterales todo un frente de la plaza central, porque curiosamente la fachada principal no da hacia la plaza, sino a una de las calles transversales que colinda además con la torre del campanario, desmembrada del edificio principal.

Esta iglesia fue construida en la época colonial, conjuntamente con la plaza en la fundación de Alvarado. Luego sufrió reconstrucciones y el techo de paja original se cambió por uno de tejas. Sus muros son de granito, con contrafuertes que sobresalen como grandes columnas, ornamentándose en la parte superior e inferior con una caladura de piedra con motivos zigzagueantes, tal como los frisos de las construcciones funerarias de la cultura Chachapoya (Laguna de los Cóndores, en Leymebamba). Esta característica convierte a la edificación en un símbolo de mestizaje cultural.

\section{foto 7}

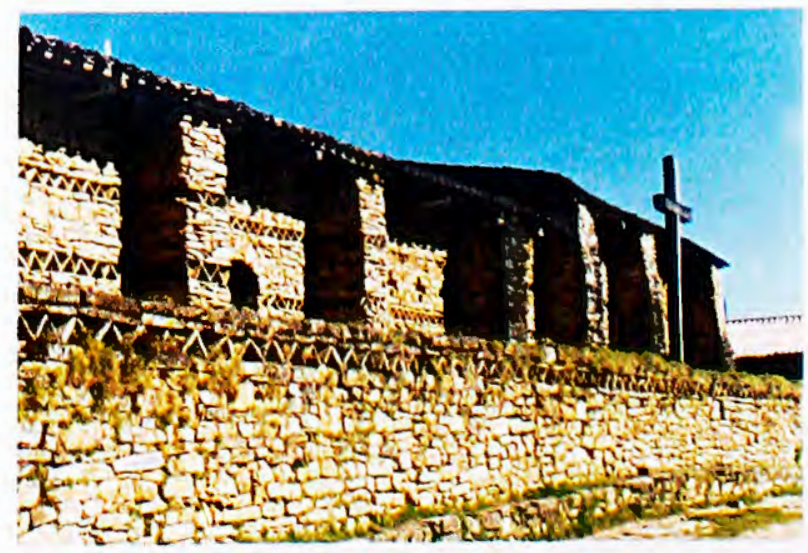




\section{VII.-Arquitectura de los caminos Yerbabuena, Ubilón y otros pueblos}

Si salimos de La Jalca hacia la carretera principal veremos una tipología de vivienda que tiene cierta similitud con la arquitectura de los pueblos de Cajamarca, pero que se distingue por el abundante uso de la madera, que va tomando un color azulado por la humedad del clima.

Esta tipología se desarrolla solamente al borde de la carretera y busca dar a la vía. Generalmente es de dos pisos y con un corredor con balcones hacia donde dan las habitaciones de la vivienda. Se accede por una escalera de madera que puede estar en el centro o en uno de los extremos; en el primer piso están normalmente los ambientes que dan hacia una galería-corredor, concebidos para el funcionamiento de una tienda o café-bar.

En este tipo de vivienda todos los ambientes de la casa dan hacia la carretera a través del balcón o corredor, mientras que la parte posterior de la casa tiene sólo unas pequeñas ventanas que dan hacia la chacra de cultivo, es decir, la carretera reemplaza al patio de las casas tradicionales y se convierte en un espacio comunicador.

Estas edificaciones están construidas con muros de tapial, estructuras y carpinteria de madera.

\section{dibujo ${ }^{\circ} 7$}
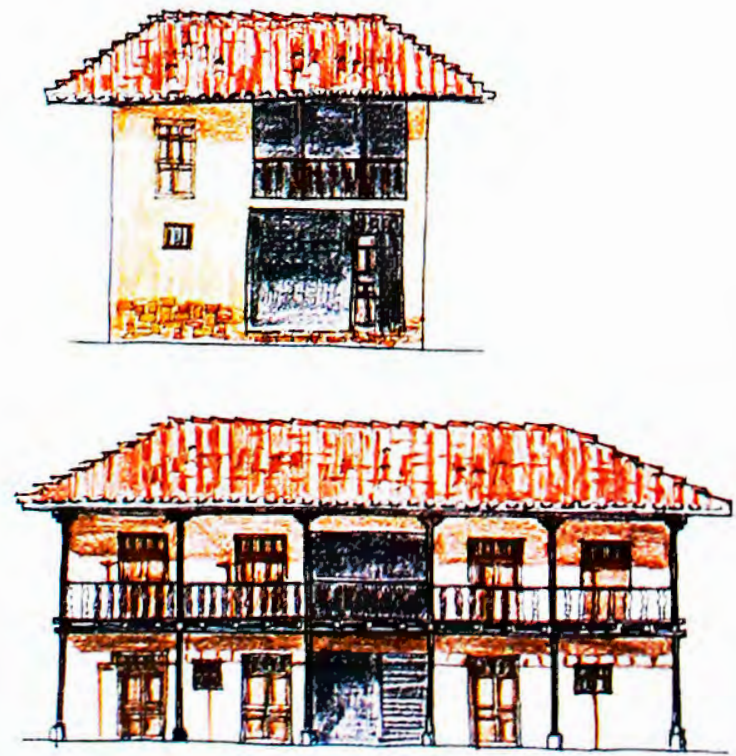

\section{VIII.-Arquitectura funeraria}

Aunque bien merecería todo un artículo, este tema se trabajará de forma muy rápida. Las edificaciones construidas en las concavidades naturales de cerros para guardar a sus muertos, como las encontradas en La Laguna de los Cóndores, Revash o Gran Pajatén, son de aproximadamente seis metros cuadrados con una altura de dos metros y medio. Construidas con muros de piedra, generalmente cubiertos con un enlucido de barro pintado, cuentan con pequeñas ventanas altas para lograr la ventilación. Estos lugares ya nos resultan familiares por aparecer las fotos de estos conjuntos que simulan agrupaciones de viviendas, con hermosos ornamentos hechos en piedra o pintados con dibujos en zigzag, rombos, cruces, etc. en un sin número de medios gráficos y escritos.

Estas edificaciones parecen ser, por las investigaciones realizadas por la doctora Sonia Guillén en la Laguna de los Cóndores, de manufactura chachapoya, pero reutilizadas por los incas luego de invadir la región.

\section{IX.- Conclusiones}

Los ejemplos aquí mostrados evidencian la particularidad de la arquitectura nor-oriental, con patrones propios de la cultura Chachapoya, que reafirman las fuertes raíces amazónicas de su arquitectura y planteamiento urbano; además de cierto grado de longevidad ya que, cuando vemos la arquitectura rural de hoy en el pueblo La Jalca, volvemos a descubrir estos criterios de diseño y tecnología.

Así hemos visto como en Kuelap y La Jalca, se tiene el mismo criterio de ocupación urbana del espacio geográfico con la irregularidad y sinuosidad a que obligan las estrechas cimas de los cerros; diferenciándose asi de la arquitectura inca que se caracteriza por su regular ortogonalidad.

Pero, tampoco podemos dejar de decir que en todos los pueblos que vamos recorriendo, nos encontramos nuevamente con los factores de cambio que ocasionan desastres como la implantación de la calamina, el ladrillo y el cemento en edificaciones ya existentes o nuevas. 


\section{BIBLIOGRAFÍA}

\author{
BONAVIA, Duccio \\ 1998 "Colonización incaica de la Selva Alta", en \\ ARKINKA n ${ }^{\circ} 34$.
}

\section{KAUFFMAN DOIG, Federico}

1997 "Los Mausoleos de la Laguna de los Cóndores", en: ARKINKA nº 97.

\section{LERCHE, Peter}

1996 Chachapoyas, Guía de Viajeros.

\author{
LERCHE, Peter \\ 1995 Los Chachapoyas y los símbolos de su his- \\ toria. Lima
}

\section{MASSON MEISS, Luis}

1995 "Ecología: El reto del Espacio Andino", en: HISTORIA Y CULTURA DEL PERU, Universidad de Lima y Museo de la Nación.
NARVAEZ VARGAS, Alfredo

1996 "La Fortaleza de Kuelap", en: ARKINKA $n^{\circ} 12$ y 13.

\section{PEÑAHERRERA DEL AGUILA, Carlos}

1995 "El Perú: Su Geografía y Medio Ambiente", en: HISTORIA Y CULTURA DEL PERU, Universidad de Lima y Museo de la Nación.

\section{VON HAGEN, Adriana}

2000 "Nueva Iconografía Chachapoya", en: Revista Peruana de Conservación, Arte y Arqueología ICONOS $n^{\circ} 4$. 